\title{
Yasser's COVID-19 Discrepancy Phenomenon; a Novel Phenomenon and Effective Regimen; Retrospective- Observational Study
}

Yasser Mohammed Hassanain Elsayed ${ }^{1 *}$

${ }^{1}$ Damietta Health Affairs, Egyptian Ministry of Health (MOH), Damietta, Egypt.

*Corresponding Author: Yasser Mohammed Hassanain Elsayed, Damietta Health Affairs, Egyptian Ministry of Health (MOH), Damietta, Egypt.

Received date: June 15, 2021; Accepted date: June 30, 2021; Published date: July 12, 2021

Citation: Elsayed Y M H, (2021). Yasser's COVID-19 Discrepancy Phenomenon: A Novel Phenomenon and Effective Regimen; RetrospectiveObservational Study. J Clinical Research and Reports, 8(4); DOI:10.31579/2690-1919/185

Copyright: (c) 2021, Elsayed Y M H. This is an open access article distributed under the Creative Commons Attribution License, which permits unrestricted use, distribution, and reproduction in any medium, provided the original work is properly cited.

\begin{abstract}
Aim of the study: Clarification for the time of the clinical improvement after management COVID-19 pneumonia versus normal gradation of common workup is the target for the current study.

Background: COVID-19 pneumonia is a current serious international pandemic infection. Generally, in medical diseases, the clinical response is commonly parallel to laboratory and radiological improvement. This rule may be different in COVID-19 pneumonia.

Method of study and patients: The author reported retrospective-observational 47-case report series. The study was conducted in a physician outpatient clinic thorough nearly 12-months, starting from Jun 9, 2020, and, ended on May 8, 2021. All included cases were COVID-19 pneumonia and treated with conventional antibiotics, anticoagulants, and steroids

Results: The mean $\pm \mathrm{SD}$ age was: 50.08 (14.9) years, with male sex predominance $(55.32 \%)$. The mean days of clinical versus leukocytosis, neutrophilia, and lymphopenia improvement $(0.84 \pm 0.49,13.05 \pm 6.44,13.05 \pm 7.01,13.05 \pm 7.01)$. The mean \pm SD days of clinical versus CRP, D-dimer, s. ferritin, and LDH improvement $(0.84 \pm 0.49,12.2 \pm 3.25,12.2 \pm 6.21$, $12.3 \pm 5.46,20.92 \pm 9.48)$. The mean days of clinical versus radiological and electrocardiographic improvement $(0.84 \pm 0.49$, $15.74 \pm 5.25,11.45 \pm 5.45$ ). The test was statistically significant in all the above tests ( $\mathrm{p}$-value is $<.00001)$

Conclusions: Yasser's COVID-19 Discrepancy phenomenon is a novel descriptive phenomenon that is always seen in all COVID-19 pneumonia. Initial dramatic improvement of the clinical status of COVID-19 pneumonic patient, not a simultaneously after the management, not a coincide with laboratory, radiological, and electrocardiographic workup. Further larger studies for the study medical regimen with considering of "Yasser's COVID-19 Discrepancy phenomenon" is recommended.

Keywords: Covid-19; discrepancy phenomenon; effective regimen; leukocytosis; electrocardiographic; PHEIC; computerized tomography; CRP
\end{abstract}

\section{Introduction}

\section{COVID-19 patients and investigations; general and significant view}

A pandemic of Coronavirus Disease 2019 (COVID-19) had emerged in December 2019 in China causing a Public Health Emergency of International Concern (PHEIC) [1]. Clinical information, laboratory data, and computerized tomography (CT) scans have been used in the setting of COVID-19 pandemic, peripherally as part of the diagnostic work-up, but mostly to help define patient prognosis and to guide clinical management [1]. Clinical, laboratory, and imaging features have been partially characterized in some observational studies [1]. The recognition and differentiation between the more severe COVID-19 versus nonsevere patients using the general laboratory tests will be entirely valuable for clinicians in predicting the disease progression [2]. There is a strong need for recognizing the mortality predictors that permit clinicians to rapidly triage severe COVID-19 patients into Intensive care units (ICUs) 
at hospitalization [3]. Laboratory data and chest CT have been used during the COVID-19 pandemic, mainly to determine patient prognosis and guide clinical management [4].

\section{Blood elements and inflammatory markers}

Total leukocytes, neutrophils, C-reactive protein (CRP), creatinine, serum glutamic pyruvic transaminase (SGPT), serum glutamicoxaloacetic transaminase (SGOT), and lactate dehydrogenase (LDH) increase with worsening parenchymal involvement [1]. Meta-analyses revealed a significant fall in lymphocyte, monocyte, and eosinophil, hemoglobin (HB), platelet, albumin, serum sodium $\left(\mathrm{Na}^{+}\right.$, lymphocyte to CRP \% (LCR), leukocyte to C-reactive protein \% (LeCR), leukocyte to IL-6 \% (LeIR), and an increase in the neutrophil, SGPT, SGOT, total bilirubin, blood urea nitrogen, creatinine, erythrocyte sedimentation rate (ESR), C-reactive protein (CRP), Procalcitonin (PCT), lactate dehydrogenase (LDH), fibrinogen, prothrombin time (PT), d-dimer, glucose level, and neutrophil to lymphocyte ratio (NLR) in the severe group compared with the non-severe group [2]. No significant changes in white blood cells (WBC), creatine kinase (CK), troponin I, myoglobin, Interleukin 6 (IL-6), and $\mathrm{K}$ between the two groups were noted. This meta-analysis gives evidence for the triage of severe cases of COVID-19 relied on laboratory test results at the decision of critical care admission [2]. Interestingly, all COVID-19 patients showed remarkable numeric and morphologic white blood cell (WBC) abnormalities, which can differentiate the mild from severe disease infection [5]. So, hospitalized COVID-19 patients must subject to a daily complete blood count (CBC) and manual WBC differential for observing numerical and morphologic abnormalities. These changes are predictive of poor outcomes and signs of disease progression [5].

\section{Leukocytic count with its differentiation}

Current reports had revealed that the presence of leukocytosis in a proportion of COVID-19 patients presentation. Unfortunately, clinical data regards these patients are rare. An elder COVID-19 patient presented with underlying chronic disorders is more liable to have leukocytosis. These patients are more at risk to develop severe illness, higher need for ICU admission, and raised mortality rate [6].

Abnormal WBC morphology is most vigorous in monocytes and lymphocytes with more mild COVID-19 disease but these abnormalities were missing with COVID-19 disease progression [5]. There were significant differences in morphology-associated the two viruses, including elevated RNA material in monocytes, decreased RNA material in lymphocytes, and minimal hypogranular neutrophils [5]. In severe COVID-19 disease, there were remarkable neutrophilia and lymphopenia, especially, in ICU patients [5]. So, severe disease is usually accompanied by lymphopenia and leukocytosis [7]. Both abnormal cellular and humoral immunity were essential findings of non-survivors with COVID19 patients [8]. Thus, neutrophilia and lymphocytopenia were immunitylinked risk factors guide for mortality in COVID-19 patients [8]. COVID19 patients with lymphopenia must be assessed for suitable management and ICU admission [9]. A decrease in lymphocyte counts paralleled worsening parenchymal extension, along with reduced arterial oxygen partial pressure and saturation [4]. Lymphopenia and a raised neutrophil/lymphocyte $\%$ are the most harmonious abnormal hemocytometric changes and modifications that may deteriorate in the severity of COVID-19 disease [10]. Also, lymphopenia is consistently present in more than $40 \%$ of the patients across eight studies with more than 500 patients. Data from the 2002-2003 outbreak indicate that SARS may be associated with lymphopenia, leukopenia, and thrombocytopenia, elevated levels of LDH, SGOT SGPT, and creatine kinase $[4,11]$.

Indeed, the lymphocyte-to-neutrophil ratio (LNR) and neutrophil-tomonocyte ratio (NMR) are good predictors for hospitalization in severe COVID-19 infection [3].

A fourfold increase of D-dimer at hospitalization greater than $2.0 \mu \mathrm{g} / \mathrm{mL}$ is an effective predictor for in-hospital mortality in patients with COVID19. It is helpful as an early biomarker that is indicated to improve the management of COVID-19 patients [12].

\section{Inflammatory and biological markers}

Autopsies reported increasing in CRP levels in patients who died of COVID-19 infection. So, it is a good biomarker for assessing disease lethality [13]. COVID-19 patients with elevated CRP levels and elevated LDH should be assessed for suitable management and ICU admission [9].

The most frequent and consistent changes previously reported in association with worsening lung involvement, concerning increased CRP and LDH concentrations and reduced lymphocyte counts and oxygen level [14]. There is a profuse cytokine releasing with hyperferritinemia which suggests that a COVID-19 infection is part of the hyperferritinemic syndrome series [15]. Indeed, marked elevated ferritin levels can present in other non- COVID-19 diseases such as hemophagocytic lymphohistiocytosis, macrophage activation syndrome, adult-onset Still's disease, catastrophic antiphospholipid syndrome, and septic shock [15]. Several studies have shown the immunomodulatory results of ferritin and its relation to mortality and continued inflammatory effects [3]. The raised concentration of free iron is tissue hazardous which is associated with redox damage and ending with fibrosis. Iron chelation is essentially considered in the management of iron overload. Iron chelation also possesses an anti-viral and anti-fibrotic activity [15]. All four types gathered under the term "hyperferritinemic syndromes" is sharing the clinical and laboratory data with the severe form of COVID-19 several features. This similar sharing between COVID-19 and "hyperferritinemic syndromes" is meaning that the severe COVID-19 is the fifth one of hyperferritinemic syndromes [16].

\section{Chest CT in COVID-19 pneumonia}

Chest CT scan provides information on both type and degree of parenchymal involvement, the first including mostly ground-glass opacities (GGO) and consolidation, and the latter through estimating, visually or automatically, the percentage of involved lung parenchyma. A potential prognostic role of chest CT signs, especially the extent of parenchymal involvement, has been proposed [17-20]. Few studies have also combined clinical, laboratory, and chest CT signs [21, 22]. Some of these suggest that the performance of the prognostic model is better when adding CT features, while the others show that chest CT findings had insufficient prognostic power to be used in combination models [4].

The Severe Acute Respiratory Syndrome Coronavirus 2 (SARS-CoV-2), formerly known as the 2019 novel Coronavirus (2019-nCoV), is a newly emerging zoonotic agent that appeared in December 2019 and causes the Coronavirus Disease 2019 (COVID-19) [23]. After correcting for parenchymal extension, ground-glass opacities were associated with reduced platelets and increased procalcitonin, consolidation with increased CRP, and reduced O2 saturation [4]. Pulmonary lesions induced by SARS-CoV-2 infection were associated with raised inflammatory response, impaired gas exchange, and end-organ damage. Lung lesions 
probably exert a central role in COVID-19 pathogenesis and clinical presentation [4].

\section{Method of study and patients}

My case study was a retrospective-observational 47-case report series. The study was conducted in a physician outpatient clinic. The author reported the 47-cases through nearly 12-months starting from Jun 9, 2020, and, ended on May 8, 2021. (Table 1) The cases were generally investigated COVID-19 that was undergoing initial ECG, chest CT, CBC, d-dimer, s. ferritin, LDH. SGPT, SGOT, s. creatinine, blood urea, and random blood sugar, and ionized calcium. Other electrolytes, arterial blood gases (ABG), troponin test, serum albumin, and echocardiography were done in selected cases. The study considers initial and post-recovery investigation for ECG, chest CT, leukocytic count, lymphocytic count, neutrophilic count, d-dimer level, s. ferritin, and LDH. (Figure 1).

\section{Acute Dramatic Clinical Improvement}
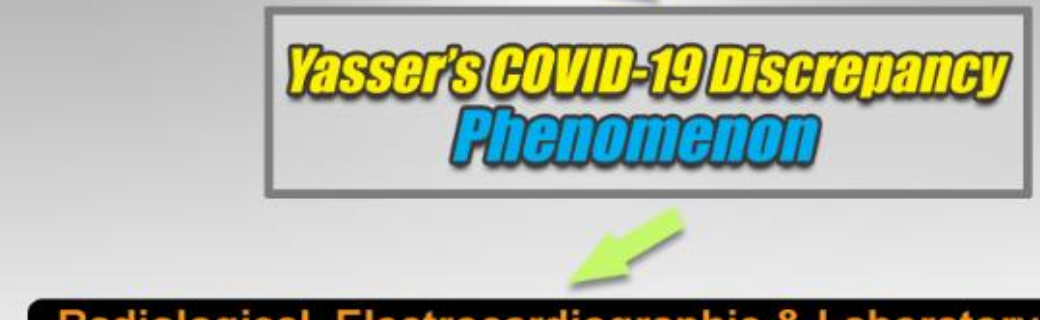

\section{Radiological, Electrocardiographic \& Laboratory Delay}
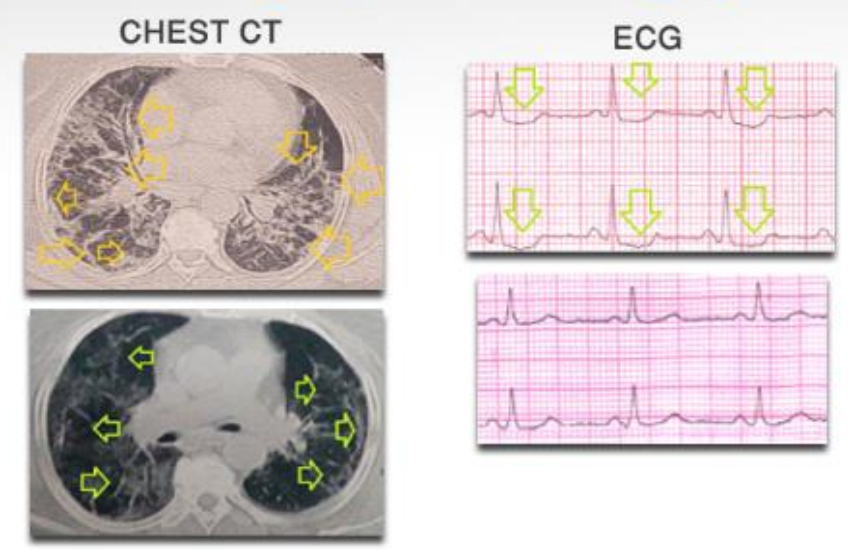

Leukocytosis

Neutrophilia

Lymphopenia

CRP

D-dimer

S. ferritin

Figure 1. Author caricaturing diagrammatic clarification for the improvement of the clinical status vs. laboratory, radiological, and electrocardiographic workup.

All cases were treated at home with cefotaxime; (1000 mg IV every 8hours), azithromycin (500 mg PO single daily dose), oseltamivir (75 mg PO twice daily only for 5 days), paracetamol (500 mg IV every 8 hours as needed), SC enoxaparin $80 \mathrm{mg}$ twice daily), aspirin tablet (75 mg, once daily), clopidogrel tablet (75 mg, once daily), and hydrocortisone sodium succinate (100 mg IV every 12 hours; was tapered with time) were added. $\mathrm{O} 2$ inhalation by $\mathrm{O} 2$ cylinder $(100 \%$, by nasal cannula, $5 \mathrm{~L} / \mathrm{min})$ was added on need. IVI fluids were sometimes given according to the clinical indications. Dose adjustment for some of the above drugs in hepatic impairment, renal impairment, cardiac, hypertensive, and diabetic patients were applied. The patient was daily monitored for temperature, pulse, blood pressure, and $\mathrm{O} 2$ saturation. For more details on general, clinical, and laboratory data for the cases see (Table 2 and 3 ).

\begin{tabular}{|c|c|c|c|c|c|c|c|c|c|}
\hline \multirow[t]{2}{*}{ Case No. } & \multirow[t]{2}{*}{ Age/y } & \multirow[t]{2}{*}{ Sex } & \multirow{2}{*}{$\begin{array}{l}\text { Pulse/ } \\
\text { bpm }\end{array}$} & \multicolumn{3}{|c|}{$\mathrm{BP} / \mathrm{mmHg}$} & \multirow[t]{2}{*}{$\begin{array}{l}\text { RR/ } \\
\text { bpm }\end{array}$} & \multirow[t]{2}{*}{ Tem $/{ }^{\circ} \mathrm{C}$} & \multirow[t]{2}{*}{$\begin{array}{l}\text { O2 } \\
\text { Sat/\% }\end{array}$} \\
\hline & & & & MAP & SBP & DBP & & & \\
\hline 1 & 71 & $\bar{F}$ & 83 & 80 & 100 & 70 & 32 & 39.6 & 91 \\
\hline 2 & 61 & $\bar{M}$ & 110 & 76.7 & 90 & 70 & 34 & 40.2 & 91 \\
\hline 3 & 60 & $\mathrm{M}$ & 160 & 100 & 140 & 80 & 40 & 39.5 & 90 \\
\hline 4 & 35 & M & 102 & 83.3 & 110 & 70 & 25 & 38 & 92 \\
\hline 5 & 60 & M & 102 & 70 & 90 & 60 & 27 & 37.5 & 90 \\
\hline 6 & 75 & $\mathrm{~F}$ & 58 & 80 & 100 & 70 & 29 & 37 & 91 \\
\hline 7 & 66 & M & 100 & 100 & 120 & 90 & 23 & 38 & 92 \\
\hline
\end{tabular}




\begin{tabular}{|c|c|c|c|c|c|c|c|c|c|}
\hline 8 & 47 & $\mathrm{M}$ & 104 & 70 & 90 & 60 & 22 & 38 & 90 \\
\hline 9 & 45 & $\mathrm{~F}$ & 78 & 90 & 130 & 70 & 32 & 37.3 & 91 \\
\hline 10 & 44 & $\mathrm{~F}$ & 98 & 76.7 & 90 & 70 & 26 & 38 & 93 \\
\hline 11 & 69 & $M$ & 72 & 83.3 & 110 & 70 & 34 & 36.7 & 91 \\
\hline 12 & 69 & $M$ & 85 & 100 & 140 & 80 & 27 & 37 & 92 \\
\hline 13 & 29 & $\mathrm{M}$ & 100 & 96.7 & 130 & 80 & 22 & 38.5 & 94 \\
\hline 14 & 65 & $\mathrm{M}$ & 72 & 110 & 150 & 90 & 25 & 37 & 92 \\
\hline 15 & 47 & $\mathrm{~F}$ & 103 & 80 & 100 & 70 & 26 & 39 & 93 \\
\hline 16 & 57 & $\mathrm{M}$ & 79 & 90 & 110 & 80 & 26 & 39 & 90 \\
\hline 17 & 63 & $\mathrm{M}$ & 110 & 100 & 140 & 80 & 28 & 37 & 93 \\
\hline 18 & 18 & $\mathrm{~F}$ & 130 & 80 & 100 & 70 & 30 & 40 & 91 \\
\hline 19 & 48 & $\mathrm{M}$ & 98 & 76.7 & 110 & 60 & 24 & 38 & 93 \\
\hline 20 & 44 & $M$ & 100 & 76.7 & 90 & 70 & 24 & 38.5 & 91 \\
\hline 21 & 55 & $\mathrm{M}$ & 110 & 76.7 & 110 & 60 & 28 & 37.8 & 90 \\
\hline 22 & 46 & $\mathrm{M}$ & 100 & 80 & 100 & 70 & 30 & 39 & 93 \\
\hline 23 & 45 & $\mathrm{M}$ & 88 & 90 & 130 & 70 & 32 & 38 & 92 \\
\hline 24 & 55 & $\mathrm{M}$ & 91 & 80 & 100 & 70 & 27 & 39.5 & 93 \\
\hline 25 & 72 & $\mathrm{M}$ & 77 & 76.7 & 90 & 70 & 28 & 38 & 91 \\
\hline 26 & 56 & $\mathrm{~F}$ & 110 & 106.7 & 140 & 90 & 36 & 39.5 & 90 \\
\hline 27 & 35 & $\mathrm{~F}$ & 90 & 76.7 & 90 & 70 & 28 & 37 & 90 \\
\hline 28 & 55 & $\mathrm{M}$ & 100 & 106.7 & 140 & 90 & 26 & 37 & 95 \\
\hline 29 & 30 & $\mathrm{~F}$ & 98 & 86.7 & 120 & 70 & 23 & 37 & 95 \\
\hline 30 & 70 & $\mathrm{~F}$ & 96 & 80 & 100 & 70 & 27 & 38 & 90 \\
\hline 31 & 40 & $\mathrm{M}$ & 102 & 76.7 & 90 & 70 & 33 & 39 & 91 \\
\hline 32 & 61 & $\mathrm{M}$ & 100 & 106.7 & 140 & 90 & 25 & 37.5 & 92 \\
\hline 33 & 72 & $\mathrm{M}$ & 88 & 76.7 & 110 & 60 & 29 & 40 & 90 \\
\hline 34 & 28 & $\mathrm{~F}$ & 94 & 96.7 & 130 & 80 & 24 & 38 & 94 \\
\hline 35 & 33 & $\mathrm{M}$ & 100 & 76.7 & 90 & 70 & 30 & 40 & 91 \\
\hline 36 & 44 & $\mathrm{M}$ & 90 & 100 & 140 & 80 & 23 & 38.5 & 96 \\
\hline 37 & 75 & $\mathrm{~F}$ & 95 & 83.3 & 110 & 70 & 40 & 39.7 & 88 \\
\hline 38 & 61 & $\mathrm{~F}$ & 100 & 76.7 & 110 & 60 & 24 & 38 & 90 \\
\hline 39 & 30 & $\mathrm{~F}$ & 85 & 90 & 110 & 80 & 22 & 37 & 95 \\
\hline 40 & 47 & $\mathrm{~F}$ & 115 & 83.3 & 110 & 70 & 26 & 38.5 & 93 \\
\hline 41 & 44 & $\mathrm{~F}$ & 68 & 70 & 90 & 60 & 27 & 39 & 94 \\
\hline 42 & 34 & $\mathrm{~F}$ & 110 & 83.3 & 110 & 70 & 24 & 40 & 93 \\
\hline 43 & 38 & $\mathrm{~F}$ & 57 & 100 & 140 & 80 & 22 & 36.5 & 96 \\
\hline 44 & 48 & $\mathrm{M}$ & 90 & 90 & 130 & 70 & 22 & 37 & 97 \\
\hline 45 & 27 & $\mathrm{~F}$ & 100 & 86.7 & 120 & 70 & 28 & 38 & 93 \\
\hline 46 & 48 & $\mathrm{~F}$ & 88 & 96.7 & 130 & 80 & 25 & 38 & 93 \\
\hline 47 & 32 & $\mathrm{~F}$ & 105 & 76.7 & 110 & 60 & 21 & 37 & 95 \\
\hline Mean & 50.08 & M :26 & 95.55 & 86.18 & 113.4 & 72.55 & 27.36 & 38.21 & 92.14 \\
\hline Mode & 44 & $\mathrm{~F} ; 21$ & 100 & 76.7 & 110 & 70 & 27 & 38 & 91 \\
\hline Median & 48 & - & 98 & 83.3 & 110 & 70 & 27 & 38 & 92 \\
\hline $\begin{array}{l}\text { Minimu } \\
\mathrm{m}\end{array}$ & 18 & - & 57 & 70 & 90 & 60 & 21 & 40.2 & 88 \\
\hline $\begin{array}{l}\text { Maximu } \\
\mathrm{m}\end{array}$ & 75 & - & 160 & 106.7 & 140 & 90 & 40 & 36.5 & 97 \\
\hline SD & 14.9 & - & 17.23 & 10.98 & 18.45 & 8.71 & 4.51 & 1.06 & 1.97 \\
\hline$P$-value & \multicolumn{9}{|c|}{ The $\mathrm{p}$-value is $<.00001$. The result is significant at $\mathrm{p}<.05$. } \\
\hline
\end{tabular}

DBP; Diastolic blood pressure; ECG; Electrocardiography, F; Female, M; Male , MAP; Mean arterial pressure, O2 Sat; Oxygen saturation, RR; Respiratory rate, SBP; Systolic blood pressure; Tem; Temperature

\section{Table-2: Summary of the history and clinical data for all the study cases.}




\begin{tabular}{|c|c|c|c|c|c|c|c|c|c|c|}
\hline $\begin{array}{l}\text { Case } \\
\text { No. }\end{array}$ & $\begin{array}{l}\text { Clinica } \\
1\end{array}$ & $\begin{array}{l}\text { Leukocytosi } \\
\mathrm{s}\end{array}$ & $\begin{array}{l}\text { Neutrophili } \\
\text { a }\end{array}$ & $\begin{array}{l}\text { Lymphope } \\
\text { nia }\end{array}$ & CRP & $\begin{array}{l}\text { D- } \\
\text { dimer }\end{array}$ & \begin{tabular}{|l|} 
S. \\
ferriti \\
$n$
\end{tabular} & LDH & $\begin{array}{l}\text { Radiolo } \\
\text { gical } \\
\text { (Chest } \\
\text { CT) }\end{array}$ & ECG \\
\hline 1 & 0.5 & 13 & $\mathrm{~N}$ & $\mathrm{~N}$ & 21 & 13 & 13 & 28 & 25 & 25 \\
\hline 2 & 1 & $\mathrm{~N}$ & 11 & 11 & 16 & $\mathrm{~N}$ & 10 & 21 & 12 & 19 \\
\hline 3 & 2 & $\mathrm{~N}$ & 32 & 32 & 12 & 19 & 19 & 27 & 20 & 36 \\
\hline 4 & 1 & 9 & 9 & 9 & 19 & 19 & 19 & 23 & 19 & 11 \\
\hline 5 & 1 & 11 & 8 & 8 & 8 & 22 & 22 & 29 & 15 & 16 \\
\hline 6 & 1 & $\mathrm{~N}$ & 28 & 28 & 15 & 12 & 12 & 18 & 12 & 17 \\
\hline 7 & 1 & 10 & 10 & 10 & 15 & 10 & \begin{tabular}{|l|}
14 \\
\end{tabular} & 21 & 17 & 14 \\
\hline 8 & 1.5 & 13 & $\mathrm{~N}$ & $\mathrm{~N}$ & 9 & 9 & $\mathrm{~N}$ & $\mathrm{~N}$ & 13 & 8 \\
\hline 9 & 0.5 & 17 & 17 & 17 & 22 & 22 & 22 & 28 & 17 & 11 \\
\hline 10 & 0.5 & $\mathrm{~N}$ & $\mathrm{~N}$ & $\mathrm{~N}$ & 10 & 17 & 10 & $\mathrm{~N}$ & 20 & 12 \\
\hline 11 & 0.5 & 9 & 9 & 9 & 9 & 9 & 9 & 17 & 12 & 14 \\
\hline 12 & 2 & 11 & 11 & 11 & 8 & 13 & 13 & 21 & 16 & 19 \\
\hline 13 & 1 & 14 & 14 & 14 & 10 & 7 & \begin{tabular}{|l|}
11 \\
\end{tabular} & 22 & 13 & 8 \\
\hline 14 & 1 & 10 & 10 & 10 & 11 & 11 & 11 & 17 & 26 & 6 \\
\hline 15 & 0.5 & 13 & 13 & 13 & 9 & 12 & \begin{tabular}{|l|}
13 \\
\end{tabular} & 24 & 19 & 15 \\
\hline 16 & 0.5 & 12 & 12 & 12 & 11 & 9 & 9 & 28 & 14 & 9 \\
\hline 17 & 0.5 & $\mathrm{~N}$ & 9 & 9 & 14 & 8 & 8 & 32 & 10 & 17 \\
\hline 18 & 0.5 & 19 & 19 & 19 & 19 & 19 & $\mathrm{~N}$ & 24 & 9 & 8 \\
\hline 19 & 0.5 & 17 & 17 & 17 & 16 & 16 & \begin{tabular}{|l|}
17 \\
\end{tabular} & 27 & 13 & 11 \\
\hline 20 & 0.5 & $\mathrm{~N}$ & 14 & 14 & 13 & 13 & 13 & 20 & 18 & 10 \\
\hline 21 & 2 & $\mathrm{~N}$ & 11 & 11 & 10 & $\mathrm{~N}$ & \begin{tabular}{|l}
$\mathrm{N}$ \\
\end{tabular} & $\mathrm{N}$ & 22 & 8 \\
\hline 22 & 1 & $\mathrm{~N}$ & 9 & 9 & 12 & $\mathrm{~N}$ & 12 & 25 & 11 & 9 \\
\hline 23 & 1 & 18 & $\mathrm{~N}$ & $\mathrm{~N}$ & 14 & 14 & \begin{tabular}{|l|}
14 \\
\end{tabular} & 19 & 12 & 6 \\
\hline 24 & 0.5 & $\mathrm{~N}$ & $\mathrm{~N}$ & $\mathrm{~N}$ & 12 & 9 & 9 & $\mathrm{~N}$ & 8 & 6 \\
\hline 25 & 0.5 & 14 & 14 & 14 & 10 & 10 & 10 & 23 & 20 & 11 \\
\hline 26 & 2 & $\mathrm{~N}$ & 17 & 17 & 14 & 14 & \begin{tabular}{|l}
14 \\
\end{tabular} & 26 & 19 & 7 \\
\hline 27 & 1 & 15 & 15 & 15 & 12 & 12 & 12 & 20 & 32 & 12 \\
\hline 28 & 0.5 & $\mathrm{~N}$ & 12 & 12 & 11 & 11 & \begin{tabular}{|l|}
11 \\
\end{tabular} & 17 & 13 & 8 \\
\hline 29 & 0.5 & $\mathrm{~N}$ & 14 & 14 & 12 & $\mathrm{~N}$ & 12 & 19 & 11 & 7 \\
\hline 30 & 0.5 & 18 & 18 & 18 & 15 & 15 & 15 & 22 & 9 & 6 \\
\hline 31 & 0.5 & 14 & 14 & 14 & 11 & 11 & \begin{tabular}{|l|}
11 \\
\end{tabular} & 20 & 24 & 9 \\
\hline 32 & 0.5 & 12 & 12 & 12 & 9 & 9 & 9 & 18 & 16 & 10 \\
\hline 33 & 1 & $\mathrm{~N}$ & 10 & 10 & 10 & 8 & 8 & 17 & 21 & 8 \\
\hline 34 & 0.5 & 11 & $\mathrm{~N}$ & $\mathrm{~N}$ & 9 & $\mathrm{~N}$ & \begin{tabular}{|l}
9 \\
9
\end{tabular} & 21 & 17 & 14 \\
\hline 35 & 0.5 & 10 & 10 & 10 & 13 & 9 & 9 & 24 & 15 & 11 \\
\hline 36 & 0.5 & 18 & 18 & 18 & 10 & 13 & 13 & 13 & 12 & 7 \\
\hline 37 & 0.5 & 17 & 17 & 17 & 14 & 14 & \begin{tabular}{|l|}
14 \\
\end{tabular} & 19 & 21 & 9 \\
\hline 38 & 2 & 14 & 14 & 14 & 12 & 10 & \begin{tabular}{|l|}
10 \\
\end{tabular} & 17 & 24 & 8 \\
\hline 39 & 1.5 & 11 & 11 & 11 & 10 & $\mathrm{~N}$ & $\mathrm{~N}$ & $\mathrm{~N}$ & 14 & 8 \\
\hline 40 & 1 & 14 & $\mathrm{~N}$ & $\mathrm{~N}$ & 13 & 13 & 13 & 22 & 18 & 16 \\
\hline 41 & 1.5 & 13 & 13 & 13 & 11 & 11 & 11 & 18 & 13 & 15 \\
\hline 42 & 0.5 & 15 & 15 & 15 & 12 & 12 & 12 & $\mathrm{~N}$ & 15 & 7 \\
\hline 43 & 0.5 & 8 & $\mathrm{~N}$ & $\mathrm{~N}$ & 11 & $\mathrm{~N}$ & $\mathrm{~N}$ & $\mathrm{~N}$ & 11 & 15 \\
\hline 44 & 0.5 & 13 & 13 & 13 & 12 & $\mathrm{~N}$ & $\mathrm{~N}$ & $\mathrm{~N}$ & 10 & 8 \\
\hline 45 & 1 & 9 & $\mathrm{~N}$ & $\mathrm{~N}$ & 9 & $\mathrm{~N}$ & $\mathrm{~N}$ & 10 & 9 & 10 \\
\hline 46 & 0.5 & 13 & 13 & 13 & 10 & $\mathrm{~N}$ & \begin{tabular}{|l|}
10 \\
\end{tabular} & 19 & 11 & 8 \\
\hline 47 & 0.5 & 9 & 9 & 9 & 9 & 9 & 9 & $\mathrm{~N}$ & 12 & 9 \\
\hline Mean & 0.84 & $13 . .05$ & $13 . .05$ & $13 . .05$ & 12.2 & 12.2 & \begin{tabular}{|l}
12.3 \\
\end{tabular} & 20.92 & 15.74 & 11.45 \\
\hline Mode & 0.5 & 13 & 14 & 13 & 12 & 9 & 9 & 17 & 12 & 8 \\
\hline Median & 0.5 & 13 & 13 & 13 & 12 & 12 & 12 & 21 & 15 & 10 \\
\hline $\begin{array}{l}\text { Minimu } \\
\mathrm{m}\end{array}$ & 0.5 & 8 & 8 & 8 & 8 & 7 & 8 & 13 & 8 & 6 \\
\hline
\end{tabular}




\begin{tabular}{|l|l|l|l|l|l|l|l|l|l|l|}
\hline $\begin{array}{l}\text { Maximu } \\
\mathrm{m}\end{array}$ & 2 & 19 & 28 & 28 & 22 & 22 & 22 & 29 & 32 & 36 \\
\hline SD & 0.49 & 6.44 & 7.01 & 7.01 & 3.25 & 6.21 & 5.46 & 9.48 & 5.25 & 5.54 \\
\hline$p$-value & \multicolumn{2}{l}{ The $\mathrm{p}$-value is $<.00001$. The result is significant at $\mathrm{p}<.05}$. \\
\hline
\end{tabular}

CRP: C-reactive protein, ECG; Electrocardiography, LDH: Lactate dehydrogenase

Table 3. The day of improvement of laboratory data for all cases

\section{- Suggesting hypothesis and research objectives}

- Suggesting hypothesis: COVID-19 pneumonia can be improved clinically in discrepancy or parallel to the laboratory, radiological and electrocardiographic workup after the management.

- The research objectives to evaluate this hypothesis might include: What is Yasser's COVID-19 Discrepancy phenomenon? Is there a paradoxical discrepancy relationship between clinical status and COVID-19 postmanagement? Is the study supported by past publicized literature studies? What is the magnitude of Yasser's COVID-19 Discrepancy phenomenon in the study?

- Response after recorded calculated days was reported post-the recovery of COVID-19 pneumonia. For more details see the summary of the study data (Table 3 ).
- All the above criteria were assessed in parallel to the clinical status vs. laboratory, radiological, and electrocardiographic workup.

- Simple selection was used in the assignment of patients for COVID-19 pneumonia.

- The treatment was administered according to international guidelines of COVID-19 pneumonia management [24-26].

- According to the response of COVID-19 pneumonia to treatment and according to "author opinion"; there are two types of response in the study;

- The "Clinical response"; It is meaning that the presence of entirely and acutely reliving general symptoms of COVID-19 pneumonia after treatment.

- The "Delayed workup response"; it is meaning that is still the presence of abnormal laboratory, radiological, and electrocardiographic workup despite there is a dramatic clinical response.

\begin{tabular}{|l|l|}
\hline Issue & Definition \\
\hline Title & $\begin{array}{l}\text { Yasser's COVID-19 Discrepancy phenomenon; A novel } \\
\text { phenomenon and effective regimen }\end{array}$ \\
\hline Estimated enrollment & 47 participants \\
\hline Study type & Observational \\
\hline Observational model & Case-only \\
\hline Time & Retrospective \\
\hline Study date & Jun 9, 2020, and, ended on May 8, 2021 \\
\hline
\end{tabular}

\section{- Eligibility criteria:}

- Inclusion criteria: All cases with COVID-19 pneumonia. Patients' ages started from 18 and up to 75 years old.

\section{- Exclusion criteria:}

1. Non-COVID-19 pneumonia.

2. Non-COVID-19 infection.

- Study limitations: The only study limitations for the current study was absence of the confirmatory tests for COVID-19 infections.

- The patient's informed consent was taken. Ethical issues were considered.

\section{Results and findings}

The result is significant at $p<0.05$.

- One-Way Repeated Measures ANOVA test was used in statistical analysis using mean with standard deviation.

- Age averages in the study; Mean: 50.08, Mode: 44, Median: 48. The mean \pm SD age was: 50.08 (14.9) years, with male sex predominance $(55.32 \%)$.

- Sex in the study: Male (M) $55.32 \%$ (26 cases) vs. Female (F) $44.68 \%$ (21 cases). (Figure 2). 


\section{Sex in the study}

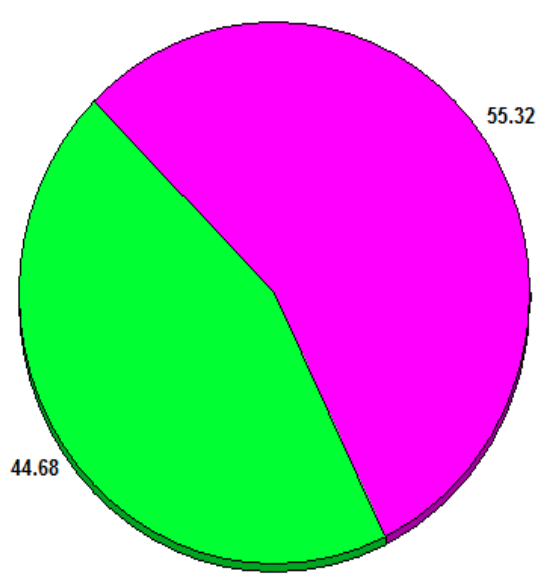

Male

Female

Figure 2. Pie-chart showing the sex in the study

\section{- The mean days of improvement}

1. The mean days of clinical versus leukocytosis, neutrophilia, and lymphopenia improvement in the study showed statistical significance (p-value is $<0.00001$ ). The mean days of clinical versus leukocytosis, neutrophilia, and lymphopenia improvement $(0.84 \pm 0.49,13.05 \pm 6.44$, $13.05 \pm 7.01,13.05 \pm 7.01$ ). (Figure 3).

\section{Olinical versus leukocytosis, neutrophilia, and lymphopenia}

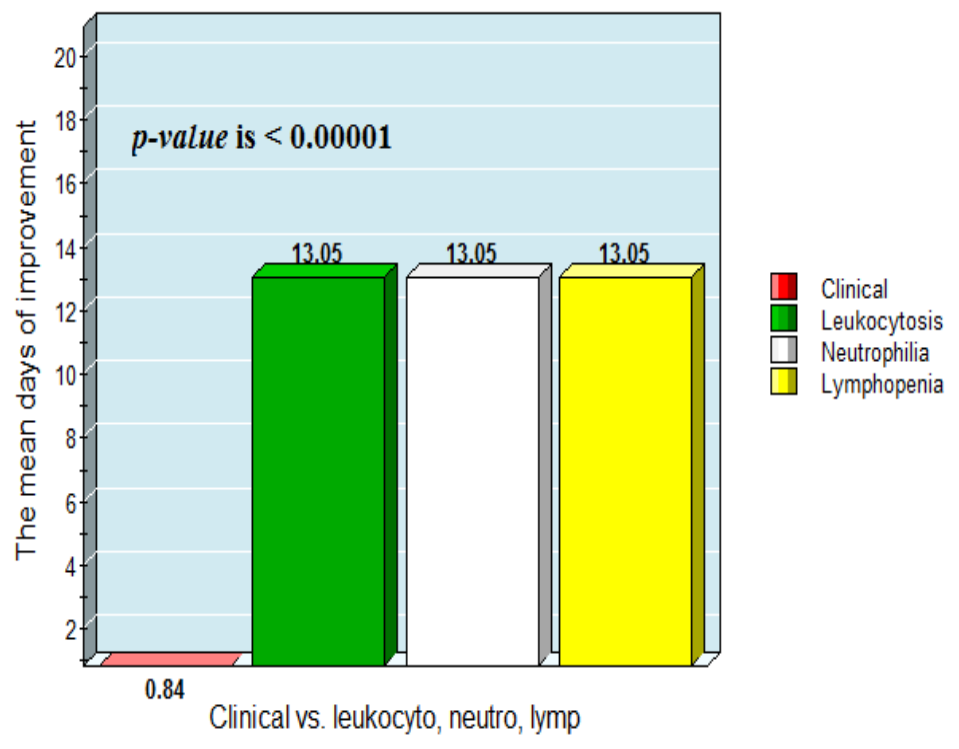

Figure 3. Bar chart showing the mean days of clinical versus leukocytosis, neutrophilia, and lymphopenia improvement in the study.

2. The day of clinical versus CRP, D-dimer, $\mathbf{s}$. ferritin, and LDH improvement in the study showed statistical significance (p-value is < $0.00001)$. The mean \pm SD days of clinical versus CRP, D-dimer, s. ferritin, and LDH improvement $(0.84 \pm 0.49,12.2 \pm 3.25,12.2 \pm 6.21,12.3$ $\pm 5.46,20.92 \pm 9.48$ ). (Figure 4). 


\section{Glinical versus GRP, D-dimer, Ferritin, LDH}

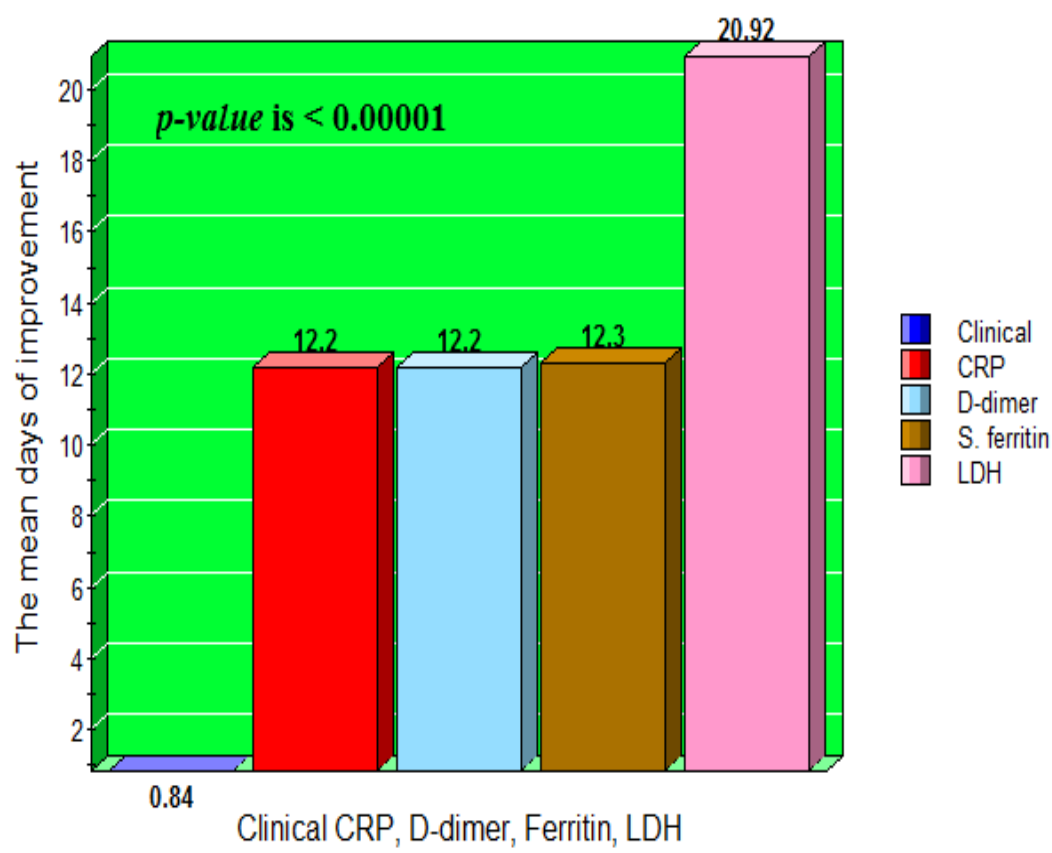

Figure 4. Bar chart showing the mean days of clinical versus CRP, D-dimer, s. ferritin, and LDH improvement in the study.

3. The mean days of clinical versus radiological and electrocardiographic improvement in the study showed statistical significance (pvalue is $<0.00001)$. The mean days of clinical versus radiological and electrocardiographic improvement $(0.84 \pm 0.49,15.74 \pm 5.25,11.45$ \pm 5.45 ). (Figure 5).

\section{Olinical versus radiological and electrocardiographic}

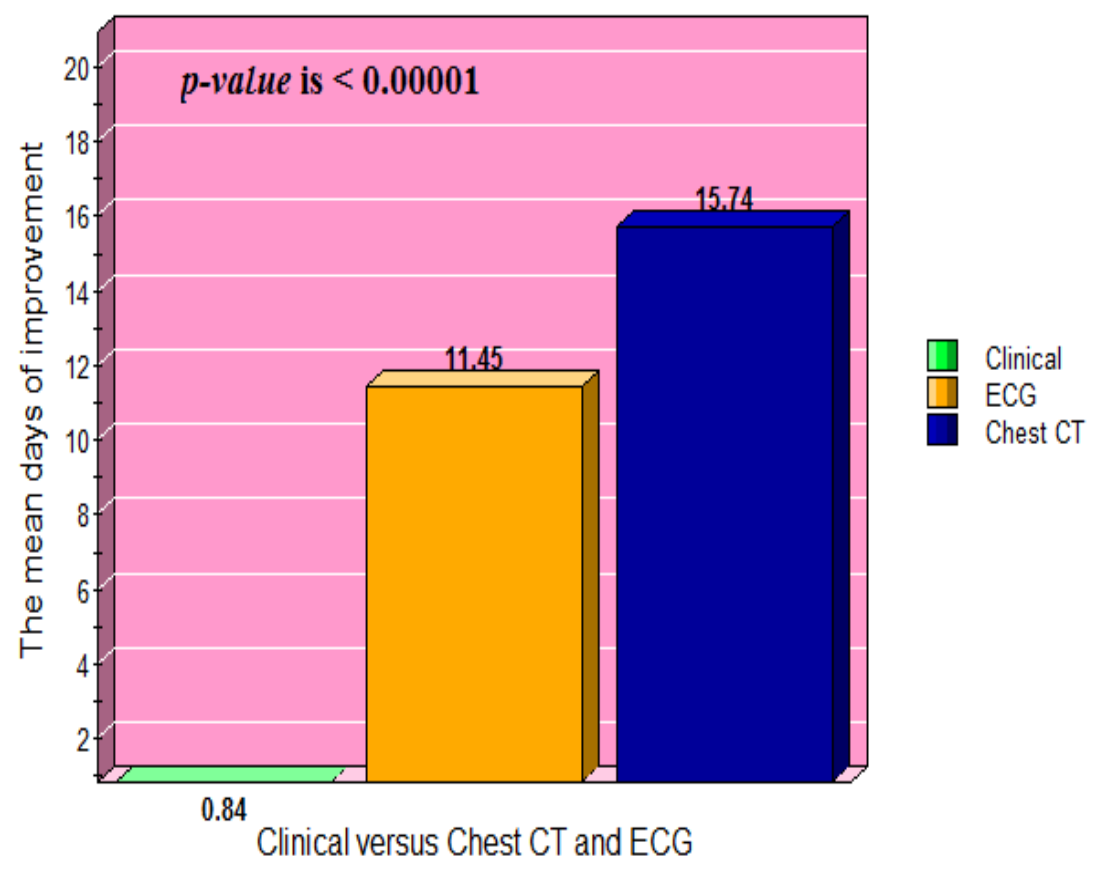

Figure 5. Bar chart showing the mean days of clinical versus radiological and electrocardiographic improvement in the study. 


\section{Discussion}

- Generally, in medical diseases, the clinical response is commonly parallel to laboratory and radiological improvement.

- So, there is a direct relationship between clinical status and laboratory workup.

- But, the author revealed that there are deviations between the clinical response or improvement and the improvement in both laboratory, radiological, and electrocardiographic workup.

- Initial dramatic improvement of the clinical status of COVID-19 pneumonic patient, not a simultaneously after the management, not a coincide with laboratory, radiological, and electrocardiographic workup.

- Unfortunately, no relevant studies are taking into consideration the time for identifying the relationship of the improvement in clinical versus and workup.

- These studies mostly signifying and mention for both used drugs and needed laboratory, radiological, and work up with no focusing on the above relationship between clinical status and laboratory workup.

- Yasser's COVID-19 Discrepancy phenomenon is an explaining phenomenon for the above relationship in COVID-19 pneumonia.

- Yasser's COVID-19 Discrepancy phenomenon is a novel descriptive phenomenon that is always seen in all COVID-19 pneumonia.

- Yasser's COVID-19 Discrepancy phenomenon is happening after giving the following medical regimen; cefotaxime; (1000 mg IV every 8hours), azithromycin (500 mg PO single daily dose), oseltamivir (75 mg PO twice daily only for 5 days), paracetamol (500 mg IV every 8 hours as needed), SC enoxaparin $80 \mathrm{mg}$ twice daily), aspirin tablet (75 mg, once daily), clopidogrel tablet ( $75 \mathrm{mg}$, once daily), and hydrocortisone sodium succinate (100 mg IV every 12 hours; was tapered with time) were added. $\mathrm{O} 2$ inhalation by $\mathrm{O} 2$ cylinder $(100 \%$, by nasal cannula, $5 \mathrm{~L} / \mathrm{min})$ was added on need. IVI fluids were sometimes given according to the clinical indications. Dose adjustment for some of the above drugs in hepatic impairment, renal impairment, cardiac, hypertensive, and diabetic patients were applied. The patient was daily monitored for temperature, pulse, blood pressure, and $\mathrm{O} 2$ saturation. The duration of this regimen is variable according to the improvement in the laboratory, radiological, and electrocardiographic workup but not the clinical status.

- In this phenomenon, there dramatic acute clinical improvement after management with the above regimen but there are delays in improvement with the time variation for the laboratory, radiological, and electrocardiographic workup (Figure 1).

- This regimen was given according to the international guidelines for COVID-19 pneumonia [24-26] but with some variations in the duration of management, type, and the number of used medications. Vitamin C and Zinc preparations were quietly excluded in this study.

\section{Conclusions:}

- "Yasser's COVID-19 Discrepancy phenomenon" is a novel descriptive phenomenon that is always seen in all COVID-19 pneumonia.

- Initial dramatic improvement of the clinical status of COVID-19 pneumonic patient, not a simultaneously after the management, not a coincide with laboratory, radiological, and electrocardiographic workup.
- Further larger studies for the study medical regimen with considering of "Yasser's COVID-19 Discrepancy phenomenon" is recommended.

\section{Conflicts of interest:}

There are no conflicts of interest.

\section{Acknowledgment:}

I wish to thank Dr. Ameer Mekkawy; M.sc. for technical support and my wife to save time and improving the conditions for helping me.

\section{References}

1. Rodriguez-Morales AJ, Cardona-Ospina JA, GutiérrezOcampo E, Villamizar-Peña R, Holguin-Rivera Y, Latin American Network of Coronavirus Disease 2019-COVID-19 Research (LANCOVID-19), et al. (2020). Clinical, laboratory and imaging features of COVID-19: A systematic review and meta-analysis. Travel Med Infect Dis. 2020 MarApr; 34:101623. Epub 2020 Mar 13.

2. Ghahramani S, Tabrizi R, Lankarani KB, Kashani SMA, Rezaei S, Zeidi N, Akbari M, Heydari ST, Akbari H, Nowrouzi-Sohrabi P, Ahmadizar F. Laboratory features of severe vs. non-severe COVID-19 patients in Asian populations: a systematic review and meta-analysis. Eur $J$ Med Res. 2020 Aug 3; 25(1):30.

3. Rizo-Téllez SA, Méndez-García LA, Flores-Rebollo C, Alba-Flores F, Alcántara-Suárez R, Manjarrez-Reyna AN, et al. The Neutrophil-to-Monocyte Ratio and Lymphocyte-toNeutrophil Ratio at Admission Predict In-Hospital Mortality in Mexican Patients with Severe SARS-CoV-2 Infection (Covid-19). Microorganisms. 2020 Oct 10; 8(10):1560.

4. Canovi, S., Besutti, G., Bonelli, E. et al. The association between clinical laboratory data and chest CT findings explains disease severity in a large Italian cohort of COVID19 patients. BMC Infect Dis. 2021; 21(157):1-9.

5. Pozdnyakova O, Connell NT, Battinelli EM, Connors JM, Fell G, Kim AS. Clinical Significance of CBC and WBC Morphology in the Diagnosis and Clinical Course of COVID-19 Infection. Am J Clin Pathol. 2020 Dec 3:aqaa23.

6. Zhao K, Li R, Wu X, Zhao Y, Wang T, Zheng Z, Zeng S, Ding X, Nie H. Clinical features in 52 patients with COVID19 who have increased leukocyte count: a retrospective analysis. Eur J Clin Microbiol Infect Dis. 2020 Dec; 39(12):2279-2287. DOI: 10.1007/s10096-020-03976-8. Epub 2020 Jul 10.

7. Huang G, Kovalic AJ, Graber CJ. Prognostic Value of Leukocytosis and Lymphopenia for Coronavirus Disease Severity. Emerg Infect Dis. 2020 Aug; 26(8):1839-1841. DOI: 10.3201/eid2608.201160. Epub 2020 May 8.

8. Zhao Y, Nie HX, Hu K, Wu XJ, Zhang YT, Wang MM, Wang T, Zheng ZS, Li XC, Zeng SL. Abnormal immunity of non-survivors with COVID-19: predictors for mortality. Infect Dis Poverty. 2020 Aug 3; 9(1):108.

9. Zhang ZL, Hou YL, Li DT, Li FZ. Laboratory findings of COVID-19: a systematic review and meta-analysis. Scand $J$ Clin Lab Invest. 2020 Oct; 80(6):441-447. DOI: 10.1080/00365513.2020.1768587. Epub 2020 May 23.

10. Khartabil TA, Russcher H, van der Ven A, de Rijke YB. A summary of the diagnostic and prognostic value of hemocytometry markers in COVID-19 patients. Crit Rev Clin Lab Sci. 2020 Sep; 57(6):415-431.

11. Tsang KW, Ho PL, Ooi GC, Yee WK, Wang T, Chan-Yeung M, Lam WK, Seto WH, Yam LY, Cheung TM, Wong PC, Lam B, Ip MS, Chan J, Yuen KY, Lai KN. A cluster of cases 
of severe acute respiratory syndrome in Hong Kong. $N$ Engl J Med. 2003 May 15; 348(20):1977-85.

12. Zhang L, Yan X, Fan Q, Liu H, Liu X, Liu Z, Zhang Z. Ddimer levels on admission to predict in-hospital mortality in patients with Covid-19. J Thromb Haemost. 2020 Jun; 18(6):1324-1329.

13. Sahu BR, Kampa RK, Padhi A, Panda AK. C-reactive protein: A promising biomarker for poor prognosis in COVID-19 infection. Clin Chim Acta. 2020 Oct; 509:91-94.

14. Yang S, Shi Y, Lu H, et al. Clinical and CT features of early stage patients with COVID-19: a retrospective analysis of imported cases in Shanghai, China. Eur Respir J. 2020.

15. Perricone C, Bartoloni E, Bursi R, Cafaro G, Guidelli GM, Shoenfeld Y, Gerli R. COVID-19 as part of the hyperferritinemic syndromes: the role of iron depletion therapy. Immunol Res. 2020 Aug; 68(4):213-224.

16. Colafrancesco S, Alessandri C, Conti F, Priori R. COVID-19 gone bad: A new character in the spectrum of the hyperferritinemic syndrome? Autoimmun Rev. 2020 Jul; 19(7):102573.

17. Li K, Fang Y, Li W, Pan C, Qin P, Zhong Y, Liu X, et al. CT image visual quantitative evaluation and clinical classification of coronavirus disease (COVID-19). Eur Radiol. 2020.

18. Yuan M, Yin W, Tao Z, Tan W, Hu Y. Association of radiologic findings with mortality of patients infected with 2019 novel coronavirus in Wuhan, China. PLoS One. 2020; 15:e0230548.

19. Wang K, Kang S, Tian R, Zhang X, Zhang X, Wang Y. Imaging manifestations and diagnostic value of chest $\mathrm{CT}$ of coronavirus disease 2019 (COVID-19) in the Xiaogan area. Clin Radiol. 2020; 75(5):341-347.

20. Lyu P, Liu X, Zhang R, Shi L, Gao J. The performance of chest $\mathrm{CT}$ in evaluating the clinical severity of COVID-19 pneumonia: identifying critical cases based on CT characteristics. Investig Radiol. 2020.

21. Wynants L, Van Calster B, Bonten MM, Collins GS, Debray T, De Vos M, Haller MC, et al. (2020). Prediction models for diagnosis and prognosis of covid-19 infection: systematic review and critical appraisal. $B M J$.

22. Colombi D, Bodini FC, Petrini M, Maffi G, Morelli N, Milanese G, Silva M, et al. Well-aerated lung on admitting chest CT to predict adverse outcome in COVID-19 pneumonia. Radiology. 2020.

23. Bonilla-Aldana D.K., Dhama K., Rodriguez-Morales A.J. Revisiting the one health approach in the context of COVID19: a look into the ecology of this emerging disease. $A d v$ Anim Vet Sci. 2020; 8:234-237.

24. National Institutes of Health. COVID-19 Treatment Guidelines Panel. Coronavirus Disease 2019 (COVID-19) Treatment Guidelines. (Accessed Dec. 25, 2020).

25. National Institutes of Health. COVID-19 Treatment Guidelines Panel. Coronavirus Disease 2019 (COVID-19) Treatment Guidelines. (Accessed Jun. 14, 2021).

26. Kumar P, Sah AK, Tripathi G, Kashyap A, Tripathi A, Rao R, Mishra PC, Mallick K, Husain A, Kashyap MK. Role of ACE2 receptor and the landscape of treatment options from convalescent plasma therapy to the drug repurposing in COVID-19. Mol Cell Biochem. 2021 Feb; 476(2):553-574. DOI: 10.1007/s11010-020-03924-2. Epub 2020 Oct 7. PMID: 33029696; PMCID: PMC7539757.

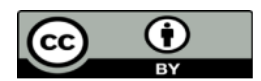

This work is licensed under Creative Commons Attribution 4.0 License

\section{To Submit Your Article Click Here: Submit Manuscript}

DOI: $10.31579 / 2690-1919 / 185$
Ready to submit your research? Choose Auctores and benefit from:

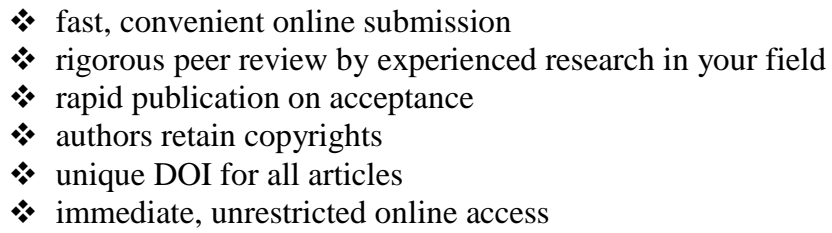

At Auctores, research is always in progress.

Learn more auctoresonline.org/journals/journal-of-clinical-research-andreports 